\title{
Mixed Ligand Copper (II) Complex with Isoniazid and Pyrazinamide
}

\author{
Dr.D.K.Tyagi, ${ }^{1}$ Satish kumar $^{2}$ \\ ${ }^{1}$ Department of chemistry,M.M.(P.G)College Modinagar U.P. India \\ 2Department of Chemistry (Research Scholar)M.M(P.G.) College modinagar U.P India
}

\begin{abstract}
The fact that the pharmacological action of certain drugs was due to the formation of chelates with essential or trace metal ions of biological significance prompted many research workers all over the world to investigate the structural features of the metal chelates of drug substances both in solid state and in solution.

So it was considered interesting and useful to study the metal complexes of drugs using various physico-chemical methods.

It is proposed to study the metal binding characteristics of some selected pharmaceuticals mentioned below.

Isoniazid, a common anti-tuberculosis drug, was shown to form complexes with metal ions like, $\mathrm{Fe}^{2+}$, $\mathrm{Co}^{2+}, \mathrm{Ni}^{2+}, \mathrm{Cu}^{2+}$ and $\mathrm{Zn}^{2+}{ }^{(1)}$. Isoniazid was shown to form both 1:1 and 1:2 complexes with copper, binding through oxygen and amino nitrogen. ${ }^{(2-3)}$

Pyrazinamide, another anti-tuberculosis drug was reported to form metal complexes of the type $M X_{2}$, $4 L$ where $M=C o(I I), N i(I I), C u(I I)$ and $X=\mathrm{Cl}^{-1}, \mathrm{Br}^{-}, I^{-}$. Besides thermal and spectral studies of these complexes, ESR spectral study was also made for the copper complex. ${ }^{(4)}$ Nickel was also shown to form neutral 1:2 complex with pyrazinamide.
\end{abstract}

Keyword: Isoniazid,Pyrazinamide

\section{Introduction}

Pyazinamide occurs as a white crystalline powder, practically insoluble in water, slightly soluble in acetone, alcohol and chloroform. The combination of pyrazinamide with other anti-tubercular drugs such as isoniazid is highly effective. The pKa value for pyrazinamide is $0.5{ }^{(5)}$<smiles>NC(=O)c1cnccn1</smiles>

\section{Instrumentation}

\section{Experimental procedure}

For thermogravimetric analysis: Stanton Redcroft STA780 Apratus was used.

For IR spectra: Nujol mull SP1200 was used

For Magnetic susceptibility Measurment:Cahn2000 magnetic balance(faraday) was used, using $\mathrm{Hg}\left[\mathrm{Co}(\mathrm{NCS})_{4}\right]$ as calibrent.

\section{Material used}

All metal salts used in synthesizing complexes were available commercially and their purity was 99 percent or above

Isoniazid (Wilson Laboratories, Bombay), Pyrazinamide (Wilson Laboratories, Bombay),

\section{Common organic solvent:}

Distilled water.Sodium hydroxide solution,Dimethylsolfoxide

\section{Preparation of Mixed Ligand Copper(II) Complexes of Isoniazid and pyrazinamide:}

Equimolar quantities of isoniazid and pyrazinamide $(2.5 \mathrm{mmol})$ were dissolved in water $(30 \mathrm{ml})$ and the $\mathrm{pH}$ of the solution was adjustred to 6.6 by adding dilute sodium hydroxide solution. This ligand solution was then added slowly to an aqueous solution $(5 \mathrm{ml})$ of copper(II) chloride $(1.25 \mathrm{mmol})$ with continuous stirring. The stirring was continued for two hours and the resultant solution was allowed to stand overnight. A reddish orange coloured precipitate formed was filtered, washed with water and then dried in a vacuum desiccator. 


\section{Results And Discussion}

The copper(II) complex was found to be decomposing at $120^{\circ} \mathrm{C}$ and the measurement of conductivity on the millimolar solution in dimethylsulfoxide showed that the complex is neutral. The elemental analyses of the complex for copper, carbon, hydrogen and nitrogen yielded results which were found to be useful in deducing the molecular formula for the brownish orange coloured copper(II) compound (see Table1).

\section{Magnetic Susceptibility}

The effective magnetic moment, $\mu_{\text {eff }}$ calculated for the copper(II) complex from the measured magnetic susceptibility at room temperature is $1.68 \mathrm{BM}$. This lesser value of magnetic moment than that of the spin-only magnetic moment for one unpaired electron system (1.73 BM) showed the nature of magnetism in the copper(II) complex as temperature and field dependent. ${ }^{(5)}$ This kind of magnetic behaviour is due to interaction between single unpaired electrons on the separate copper(II) ions, the magnitude of which must be comparable to that of thermal energy KT (ca. $200 \mathrm{~cm}^{-1}$ ). The subnormal magnetic moment of $1.68 \mathrm{BM}$ (at room temperature) suggests that the structure of this copper(II) complex of isoniazid and pyrazinamide could be polymeric.

Table 1: Physical and Analytical Data of the Complex, [Cu(INA) (PZA-H) $(\mathrm{OH})] \mathrm{H}_{2} \mathrm{O}$

\begin{tabular}{|c|c|}
\hline Description & Results \\
\hline Colour & Brownish Orange \\
\hline Decomposition temperature $\left({ }^{\circ} \mathrm{C}\right)$ & 120 \\
\hline $\begin{array}{l}\text { Elemental analysis } \\
\text { Found (calculated) \% }\end{array}$ & \\
\hline $\begin{array}{l}\text { Copper } \\
\text { Carbon } \\
\text { Hydrogen } \\
\text { Nitrogen }\end{array}$ & $\begin{array}{c}17.22(17.76) \\
36.95(36.91) \\
3.73(3.91) \\
23.85(23.49) \\
\end{array}$ \\
\hline Magnetic moment, $\mu$ in BM & 1.68 \\
\hline $\begin{array}{l}\text { Molar conductivity, } \Lambda \mathrm{M} \\
\left(\mathrm{ohm}^{-1} \cdot \mathrm{cm}^{2} \cdot \mathrm{mol}^{-1}\right)\end{array}$ & Neutral (in DMSO) \\
\hline $\begin{array}{l}\text { Electronic Spectral Analysis } \\
\text { Diffuse Relectance Wavelength }\left(\mathrm{cm}^{-1}\right)\end{array}$ & $\begin{array}{c}40,000 \\
32,258 \\
\text { (Charge transfer band) }\end{array}$ \\
\hline
\end{tabular}

\section{Electronic Spectral Study}

The diffuse reflectance spectrum of the copper(II) complex showed two absorptions (40,000 and $32,260 \mathrm{~cm}^{-1}$ ) in the ultraviolet region corresponding to charge transfer between the metal and the ligands. Any absorption in the visible region might have been obscured by charge transfer band. ${ }^{(6)}$

\section{Infrared Spectral Study}

Infrared spectra were recorded for isoniazid, pyrazinamide and the copper(II) complex as nujol mull in the region $4000-400 \mathrm{~cm}^{-1}$.

\section{IR Region $4000-3000 \mathrm{~cm}^{-1}$}

Vibrational absorptions at $3005,3210,3165$ and $3105 \mathrm{~cm}^{-1}$ in the spectrum of isoniazid ${ }^{(7)}$ and at 3400 and $3180 \mathrm{~cm}^{-1}$ in the spectrum of pyrazinamide could be due to asymmetric and symmetric stretchings of $\mathrm{NH}$ and $\mathrm{NH}_{2}$ groupings. The infrared spectrum of the copper(II) complex exhibited a strong absorption at $3445 \mathrm{~cm}^{-1}$ probably due to $\mathrm{O}-\mathrm{H}$ stretching of water molecule along with that of $\mathrm{N}-\mathrm{H}$ stretching at 3385,3255 and 3130 $\mathrm{cm}^{-1} \cdot{ }^{(8-10)}$ The reduction in the number of vibrational bands corresponding to $\mathrm{N}-\mathrm{H}$ stretching might be due to loss of $\mathrm{NH}$ protons on complex formation. The overall negative shift in energy with respect to these vibrational frequencies in the case of copper(II) complex indicates the bond formation between the metal and the ligands (isoniazid and pyrazinamide) through amide nitrogen atoms ${ }^{(11-13)}$ (see Table 2).

\section{IR Region $2000-400 \mathrm{~cm}^{-1}$}

The carbonyl stretching vibrational bands at $1670 \mathrm{~cm}^{-1}$ (isoniazid) and $1720 \mathrm{~cm}^{-1}$ (pyrazinamide) have suffered only a slight negative shift $\left(1660\right.$ and $\left.1710 \mathrm{~cm}^{-1}\right)$ on complex formation. This suggests that the carbonyl groups might be free of metal binding in the copper(II) complex. 
Table 2: Infrared Spectral Data of Isoniazid, Pyrazinamide and the Copper(II) Complex*

\begin{tabular}{|c|c|c|c|}
\hline $\begin{array}{l}\begin{array}{l}\text { Assignment of vibrational } \\
\text { bands }\end{array} \\
\end{array}$ & Isoniazid & Pyrazinamide & {$[\mathrm{Cu}(\mathrm{INA})-(\mathrm{PZA}-\mathrm{H})-(\mathrm{OH})] \mathrm{H}_{2} \mathrm{O}$} \\
\hline$v_{\mathrm{O}-\mathrm{H}}\left(\mathrm{H}_{2} \mathrm{O}\right)$ & - & - & $3450 \mathrm{~s}$ \\
\hline$v_{\mathrm{N}-\mathrm{H}}$ & $\begin{array}{l}3305 \mathrm{~s} \\
3210 \mathrm{~s} \\
3165 \mathrm{~s} \\
3105 \mathrm{~s}\end{array}$ & $\begin{array}{c}3400 \mathrm{~s} \\
3180 \mathrm{~s} \\
- \\
-\end{array}$ & $\begin{array}{c}3280 \mathrm{~s} \\
3255 \mathrm{~b}, \mathrm{~s} \\
3130 \mathrm{~b}, \mathrm{~s} \\
-\end{array}$ \\
\hline$v_{\mathrm{C}=\mathrm{O}}$ & $\begin{array}{c}- \\
1670 \mathrm{~s}\end{array}$ & $\begin{array}{c}1720 s \\
-\end{array}$ & $\begin{array}{l}1710 \mathrm{~s} \\
1660 \mathrm{~s}\end{array}$ \\
\hline$\delta \mathrm{NH}_{2}+v_{\mathrm{O}-\mathrm{C}-\mathrm{N}}$ & $1635 \mathrm{~m}$ & $1610 \mathrm{~m}$ & - \\
\hline Amide II & $1560 \mathrm{~s}$ & $1580 \mathrm{~s}$ & $1585 \mathrm{~s}$ \\
\hline $\mathrm{v}_{\mathrm{O}-\mathrm{C}-\mathrm{N}}$ & $1380 \mathrm{~s}$ & $1380 \mathrm{~s}$ & $1400-1320 \mathrm{~b}$ \\
\hline $\mathrm{NH}$ & $\begin{array}{l}1225 \mathrm{~m} \\
1200 \mathrm{~m}\end{array}$ & $\begin{array}{l}- \\
-\end{array}$ & $\begin{array}{l}- \\
-\end{array}$ \\
\hline$v_{\mathrm{N}-\mathrm{N}}$ & $1000 \mathrm{~m}$ & - & 960 \\
\hline $\begin{array}{l}\text { Two adjacent ring } \mathrm{C}-\mathrm{H}+\delta_{\mathrm{NH}} \\
\text { (out of plane) }\end{array}$ & $\begin{array}{c}890 \mathrm{~m} \\
- \\
\end{array}$ & $\begin{array}{c}780 w \\
- \\
\end{array}$ & $\begin{array}{l}875 \mathrm{~m} \\
780 \mathrm{w}\end{array}$ \\
\hline $\begin{array}{l}\text { Pyrazine ring out of plane } \\
\text { deformation }\end{array}$ & - & $435 \mathrm{~m}$ & $455 \mathrm{~m}$ \\
\hline
\end{tabular}

* Spectra recorded in nujol; vibrational frequencies in $\mathrm{cm}^{-1}$; vibrational band description; $\mathrm{b}=\mathrm{broad}, \mathrm{s}=\mathrm{strong}$, medium $=\mathrm{m}$ and $\mathrm{w}=$ weak

Pyrazine ring vibrational bands at $1580,1525,620$ and $435 \mathrm{~cm}^{-1}$ have suffered an overall positive shift $\left(1585,1525,640\right.$ and $\left.456 \mathrm{~cm}^{-1}\right)$ in the infrared spectrum of the copper(II) complex (Fig. 6.21). This indicates that the ring nitrogen has also taken part in the metal-ligand binding. Similar observations were made by Singh and Seth in the case of cobalt(II) and nickel(II) complexes of pyrazinamides ${ }^{(14)}$.

As both the ligands, isoniazid and pyrazinamide themselves have rich infrared absorptions in the region $600-400 \mathrm{~cm}^{-1}$, assignment of infrared peaks to $\mathrm{M}-\mathrm{N}$ and $\mathrm{M}-\mathrm{O}$ stretchings was found to be difficult.

\section{Thermal Decomposition Study}

The initial decomposition of the copper(II) complex of isoniazid and pyrazinamide has occurred at $120^{\circ} \mathrm{C}$ with the loss of one water molecule (5\% by weight). Around $39 \%$ weight loss was recorded at $250^{\circ} \mathrm{C}$ probably due to loss of one more water molecule along with pyrazinamide moiety. Above $340^{\circ} \mathrm{c}$, a further decrease in the weight of the sample was noticed. ${ }^{(15)}$ Approximately $35 \%$ weight loss at this stage could possibly be due to decomposition of isoniazid moiety. Between $520^{\circ}$ and $570^{\circ} \mathrm{C}$, there existed a constant weight residue which could possibly be cuprous oxide, $\mathrm{Cu}_{2} \mathrm{O}$ accounting for $20 \%$ of the weight of the sample ${ }^{(16)}$

\section{Conclusion}

Based on these data of structural investigation on the copper(II) complex prepared, the following structure is suggested.

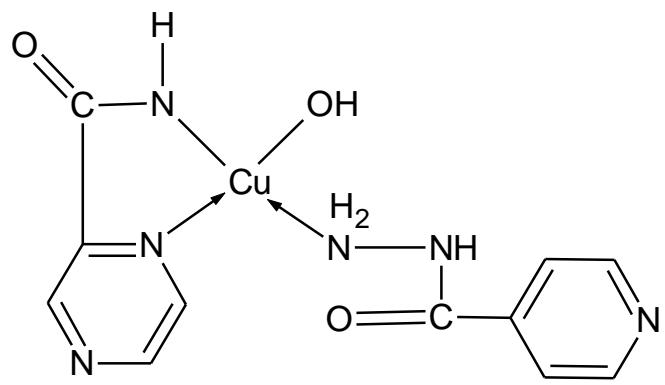

[1]. Albert, A., Nature, Lond., 177 (1956).

References

[2]. Fallab, S., and Erlenmeyer, Exper., 8, 298 (1952).

[3]. Sorkin, E., Roth, W., and Elenmeyer, H., Helv. Chim. Acta, 35, 1736 (1952).

[4]. Micu-Semeniuc, Rodica., Sanda, Maria., and Craciun, Cristina., Stud. Univ., Babes-Bolyai, (Ser) Chem., 27, 3 (1982) (Rom); Chem. Abstr., 98, 209007a (1983).

[5]. Doerge, R.F., (Ed.), "Wilson and Gisvold's Textbook of Organic Medicinal and Pharmaceutical Chemistry", $8^{\text {th }}$ Edn., J.B. Lippincott, Philadelphia 1982

[6]. Lever, A.B.P., (Ed.), "Inorganic Electronic Spectroscopy", 2 ${ }^{\text {nd }}$ Edn., Elsevier, Amsterdam 1984

[7]. Mahto, C.B., J. Indian Chem. Soc., 57, 485 (1980).

[8]. Duval, C., "Inorganic Thermogravimetric Analysis", $2^{\text {nd }}$ Edn., Elsevier, Amsterdam 1963. 
[9]. Julve, M., Verdaguer, M., Gleizes, A., Philochelevisalles, M., and Kahn, O., Inorg. Chem; 23, 3808 (1984).

[10]. Gleizes, A., Julve, M., Verdaguer, M., Real, J.A., Fans, J. and Solans, X.J., J. Chem. Soc. Dalton Trans. 3209 (1992).

[11]. Castro, I., Fans, J., Julve, M., Munoz, M.C., Diaz, W. and Solans, X., Inorg. Chim. Acta 59, 179 (1991).

[12]. Bencini, A., Fabretti, A.C., Zanchinic and Zannini, P., Inorg. Chem. 26, 1445 (1987).

[13]. Thomas, A.M., Mandal, G.C., Tiwary, S.K., Rath, R.K., Chakravorty, A.R., J. Chem. Soc. Dalton Trans. 1395 (2000).

[14]. Batten, S.R., Harris, A.R., Jensen, P. Murray, K.S., and Ziebell, A., J. Chem. Soc. Dalton Trans. 3829 (2000). Chem. Commun; 2331 (2000).

[15]. Lethbridge, Z.A.D., Tiwary, S.K., Harriso, A. and Lightfoot, P., J. Chem. Soc. Dalton Trans. 1904 (2001).

[16]. Patel, R.N., Gundla, V.L.N. and Patel, D.K., Ind. J. Chem. 47A, 353 (2008). 